\title{
Improving Wind and Rain Simulations for Tropical Cyclones with the Assimilation of Doppler Radar Data
}

\author{
T.C. Cheung ${ }^{1}$ and P.W. Chan ${ }^{*}, 2$ \\ ${ }^{1}$ Chinese University of Hong Kong, Hong Kong, China \\ ${ }^{2}$ Hong Kong Observatory, Hong Kong, China
}

\begin{abstract}
More accurate prediction of the strong winds and heavy rain associated with tropical cyclones using numerical weather prediction (NWP) models would be helpful in the provision of weather services for the public. In this paper, the impact of assimilating radar data in the simulation of Typhoon Neoguri and Severe Tropical Storm Kammuri in 2008 is studied using Weather Research and Forecasting (WRF) version 2.2 and WRF VAR version 2.1. Only the data from the radar at Tate's Cairn in Hong Kong are considered. Four experiments are conducted, namely, (a) simulation without radar data, (b) simulation with radar data assimilated at the initial time, (c) cycling simulation with the assimilation of radar data (Doppler velocity and reflectivity) directly assimilated, and (d) cycling simulation with the assimilation of 2D wind field retrieved from the Doppler velocity data from the radar. By comparing with actual observations of the surface wind distribution in Hong Kong and the actual radar reflectivity data, it turns out that both (c) and (d) outperform (a) and (b), and (c) and (d) show comparable skills. As a result, cycling simulation with the assimilation of weather radar data (even for a single radar) could improve the prediction of winds and rain bands associated with tropical cyclones.
\end{abstract}

Keywords: Radar, WRF, 3DVAR, wind retrievel.

\section{INTRODUCTION}

In every summer, tropical cyclones bring about hazardous weather to coastal areas of southern China, including strong winds and heavy rain associated with the outer rain bands. Accurate forecasting of the winds and rain caused by tropical cyclones would be very useful for the provision of timely warnings for the general public. Nowadays, numerical weather prediction (NWP) models, from synoptic scale to mesoscale scale, are widely used in the weather services in forecasting heavy rain and strong wind areas brought by tropical cyclones. The performance of NWP models is gradually improved with the physical parameterizations becoming more and more sophisticated. At the same time, the assimilation of remote-sensing data covering the tropical cyclones, such as radar and satellite observations, could also help initializing the NWP models. Impact study of radar data on the simulation of tropical cyclones have been conducted for Atlantic Ocean (e.g. [1]). Similar study should be carried out for tropical cyclones over other ocean basins, such as the South China Sea.

In this paper, the impact of assimilating radar data on the model forecasting of strong wind and heavy rain areas of tropical cyclones is studied. Two tropical cyclone events over the northern part of the South China Sea and south China coastal areas in 2008 are considered, namely, Typhoon Neoguri in April and Severe Tropical Storm Kammuri in August. At the first step, only the data from a single radar in Hong Kong are used in the analysis. Such data, including the Doppler velocity and reflectivity measurements, are used in a variety of ways,

*Address correspondence to this author at the Hong Kong Observatory, 134A Nathan Road, Hong Kong; Tel: (852) 2926 8435; Fax: (852) 2375 2645; E-mail: pwchan@hko.gov.hk namely, by assimilation using a 3D variational scheme (3DVAR) of the NWP model at the initial time only, by 3DVAR assimilation in a cycling run at two separate times (with 3 hours apart), and in a cycling run but with 3DVAR assimilation of the radar-retrieved 2D wind field. The study aims at finding out which assimilation method has the strongest positive impact on the simulation results, in terms of the forecasting of strong winds and heavy rain areas of the cyclones.

This paper is organized as follows. Section 2 deals with the model setup. The radar data and their assimilation into the model are described in Section 3. Two case studies are presented in Sections 4 and 5. Conclusions are drawn in Section 6.

\section{MODEL SETUP}

The Weather Research and Forecasting (WRF) model version 2.2 [2] is employed in this study. Its simulation domain is shown in Fig. (1a). It is nested with the operational regional spectral model (ORSM) of the Hong Kong Observatory (HKO) with a spatial resolution of $20 \mathrm{~km}$. A description of ORSM could be found in [3]. WRF run is made at a resolution of $4 \mathrm{~km}$.

The model physics options used in the WRF simulation include: WRF single moment 5-class (WSM5) scheme for microphysics, rapid radiative transfer model (RRTM) for longwave radiation, MM5 (Dudhia) scheme for shortwave radiation, Monin-Obukhov scheme for surface layer, and Mellor-Yamada-Janjic (MYJ) turbulent kinetic energy scheme, but with cumulus parameterization switched off.

\section{ASSIMILATION OF RADAR DATA}

The radar considered in this study is the one located at

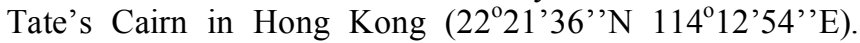




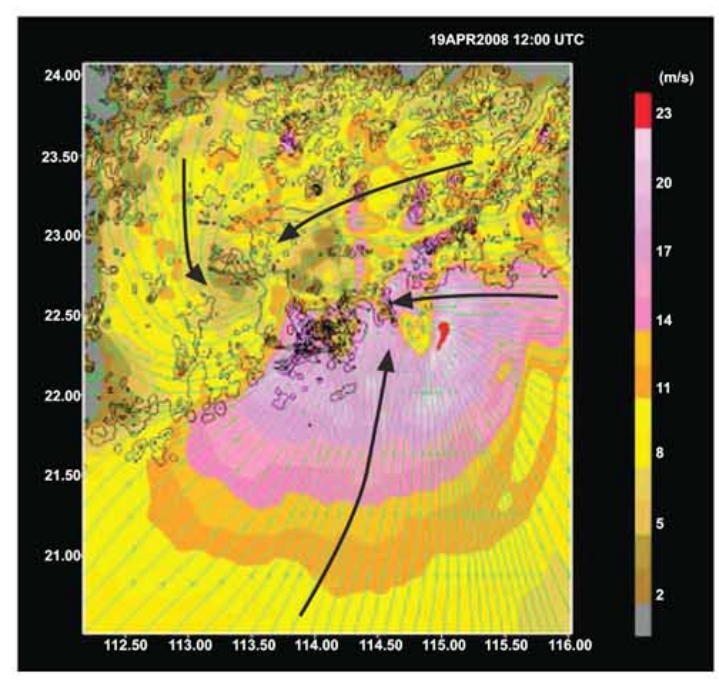

(a) cold start, no radar data

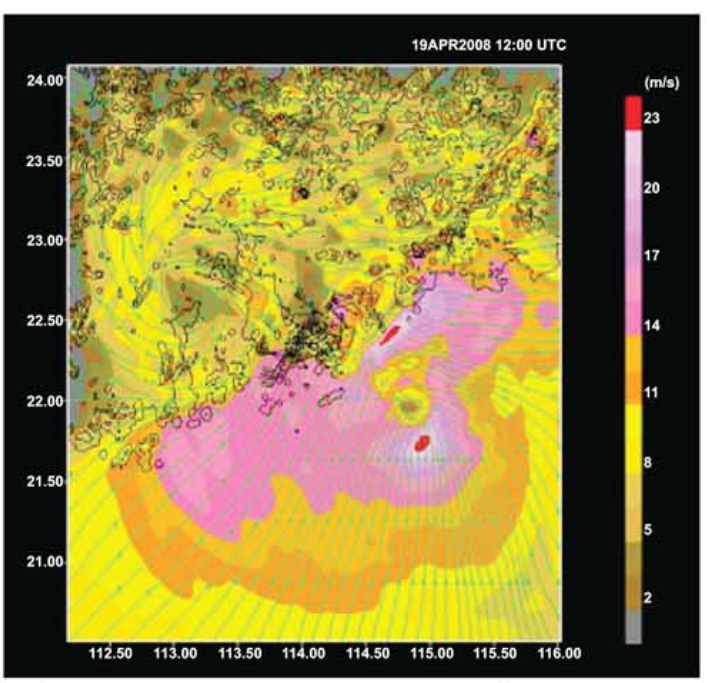

(c) cycling run, direct assimilation of radar data

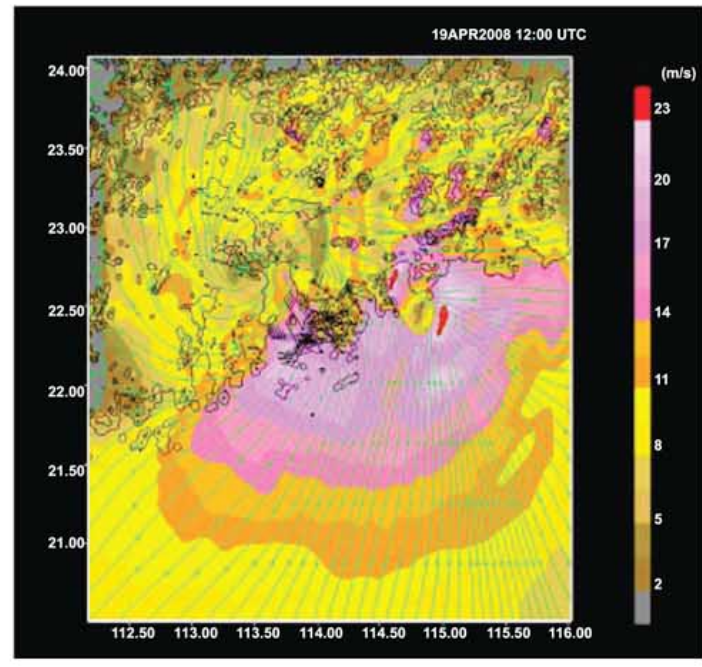

(b) cold start, with the assimilation of radar data

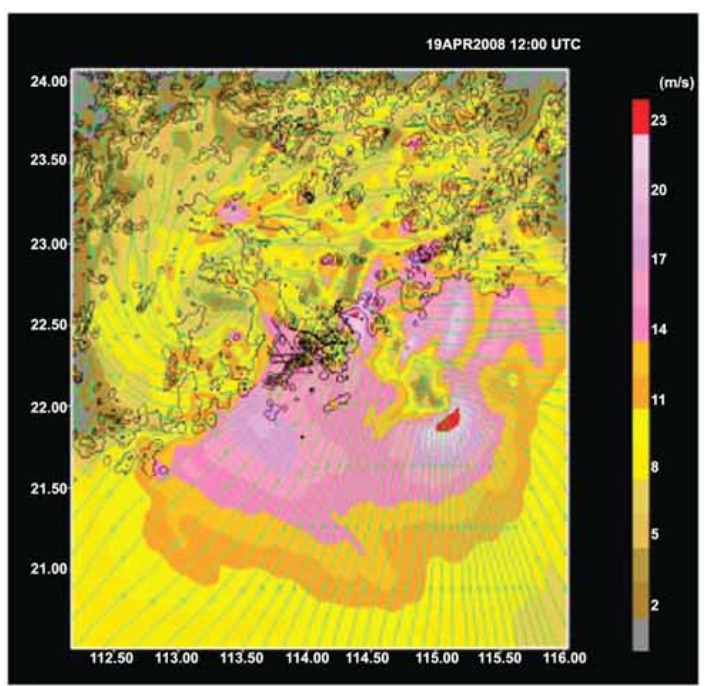

(d) cycling run, assimlating radar retrieved winds

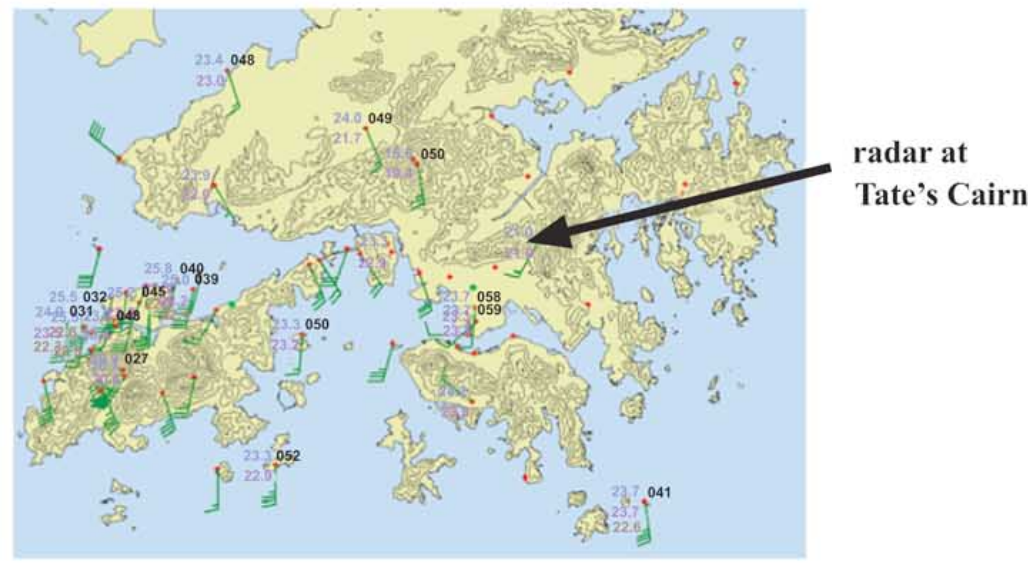

(e) actual surface wind observations in Hong Kong

Fig. (1). The simulated surface wind magnitude (coloured contours) and streamlines for the four different model runs (a-d) at 12 UTC, 19 April 2008. The black contours are height contours in $200 \mathrm{~m}$. The wind barbs over Hong Kong are simulated surface winds at the automatic weather stations within the territory. The major directions of the airflow are shown as arrows in (a). (e) shows the actual surface wind data in Hong Kong at the same time. Height contours are in $100 \mathrm{~m}$. 
Location is shown in Fig. (1e). It is an S-band radar at around $585 \mathrm{~m}$ AMSL on top of a hill with a Nyquist velocity of $35.8 \mathrm{~m} / \mathrm{s}$. It scans at 12 different elevation angles from $0.5^{\circ}$ to $34.7^{\circ}$. The volume scan takes about 6 minutes to complete. Before the variational analysis, the radar data are interpolated into a Cartesian grid. The interpolation is achieved through the radar processing software IRIS. The grid has $640 \times 640$ points with a size of $800 \mathrm{~m}$. In the vertical, the radar data extend from the ground up to $5000 \mathrm{~m}$ with a resolution of $500 \mathrm{~m}$.

The Doppler velocity and reflectivity data of Tate's Cairn radar are assimilated into WRF using WRF VAR version 2.1 [4]. The conventional weather observations, such as surface SYNOP and upper air TEMP/PILOT data, are also included in the analysis. WRF VAR is a variational data assimilation scheme to ingest both conventional and non-conventional data through the iterative minimization of a prescribed cost (or penalty) function. Differences between the analysis and the observations are penalized (damped) according to their perceived error. For simplicity, the errors of radial velocity and reflectivity are taken to be $1 \mathrm{~m} / \mathrm{s}$ and $1 \mathrm{dBZ}$ respectively.

As an experiment, apart from the direct ingestion of Doppler velocity and reflectivity data from the radar, the 2D wind field under the coverage of the radar is retrieved from the Doppler velocity data of the radar and ingested into WRF through WRF VAR. For this purpose, the two-step variational method as described in [5] is employed. This two-step variational method calculates $2 \mathrm{D}$ wind field at different heights by minimization of a cost function that takes into account the difference between the observed and the analyzed radial velocity, conservation of reflectivity and continuity of the wind field. In the assimilation into WRF, the $2 \mathrm{D}$ wind profile at a grid point is taken to be an "upperair ascent", similar to the radiosonde measurement.

\section{TYPHOON NEOGURI}

In the morning of 19 April 2008, Neoguri was located at about $300 \mathrm{~km}$ to the southwest of Hong Kong over the northern part of the South China Sea. It continued to move northwestward and made landfall over western coast of Guangdong. After making landfall, it remained on a northwesterly track over the inland areas. Neoguri brought heavy rain to Hong Kong as it traversed over inland Guangdong. Between 4 and 8 p.m. on that day (Hong Kong time $=$ UTC +8 hours), a total of 161.1 millimetres of rainfall were recorded at HKO Headquarters. This necessitated the issuance of "black rainstorm warning" in Hong Kong, which means the occurrence of widespread heavy rain over the territory with an hourly rainfall of 70 $\mathrm{mm}$ or more. Located to the north of Hong Kong, Neoguri also brought about gale-force south to southwesterly winds over the territory.

The WRF-simulated surface wind magnitude and streamlines for the different data assimilation runs are shown in Fig. (1a-d). The surface winds refer to simulated/observed values at a height of $10 \mathrm{~m}$. The simulations are made starting at 06 UTC, 19 April 2008, and the figures show the simulation results at 6 hours later. For cycling runs (Fig. 1c, d), the first simulation starts at 03 UTC, 19 April 2008 and is run for three hours, and another data assimilation is made at 06 UTC, 19 April 2008, and model forecast is run since then. It could be seen that, for the cycling simulations (c) and (d) (being respectively the direct assimilation of radar velocity and reflectivity data through WRF 3DVAR, and the assimilation of radar-derived 2D winds only obtained by [5] in WRF 3DVAR), the surface wind magnitudes over Hong Kong are generally smaller (in the order of $17 \mathrm{~m} / \mathrm{s}$ ) than those without cycling, viz. (a) and (b) (being respectively without the use of radar data at all, and the assimilation of radar velocity and reflectivity data only at 06 UTC, 19 April 2008). In the latter two runs, the surface wind magnitude in Hong Kong could reach $20 \mathrm{~m} / \mathrm{s}$. The actual observations over the territory at that time (Fig. 1e) showed that there were only gale-force winds of about $17 \mathrm{~m} / \mathrm{s}$ (35 knots). Winds of similar strength were also recorded at Huang Mao Zhou (not shown), an island weather station located at about $58 \mathrm{~km}$ south-southwest of Hong Kong. Unfortunately, there were no other surface observations over the south China coastal waters for comparison with the model simulation results.

Without the assimilation of radar data, WRF appears to over-predict the surface wind for this tropical cyclone case. To the knowledge of the authors, there does not seem to be reports in the literature about the tendency of WRF to overpredict surface winds. This over-prediction may be related to the choice of physical parameterization schemes in the model and the use of ORSM in the boundary/initial conditions. Further studies would be required to determine the origin of this surface-wind over-prediction. In any case, the assimilation of radar data helps improve the magnitude of the simulated surface wind in comparison with actual observations.

Fig. (2) gives the simulation results for rain bands associated with the landfalling tropical cyclone. In the simulations Fig. (2a, b), the heavy rain areas have already moved northeastward away from Hong Kong. On the other hand, with the cycling runs Fig. (2c, d), some heavier rain still persists over the territory at 12 UTC, 19 April 2008. Between these two runs, Fig. (2c) appears to give even better results with the occurrence of "radar echoes" of about 40 dBZ across Hong Kong. This simulated rainfall pattern is more consistent with the actual observations of the radar in Hong Kong (Fig. 2e).

Considering the rain and wind forecasts in Typhoon Neoguri, the cycling runs appear to perform better than coldstart runs. In particular, the WRF VAR assimilation of radar reflectivity and velocity data seems to reproduce the most successfully the evolution of the rain bands associated with the tropical cyclone.

\section{SEVERE TROPICAL STORM KAMMURI}

In the morning of 6 August 2008, Kammuri was located at about $130 \mathrm{~km}$ south of Hong Kong and moved to the northwest steadily across the south China coastal waters. It brought about gale-force east to southeasterly winds to Hong Kong. Moreover, the outer rain bands associated with Kammuri affected the coast of Guangdong.

Model simulations start at 00 UTC, 6 August 2008. For cycling run, the first simulation is made at 21 UTC, 5 August 


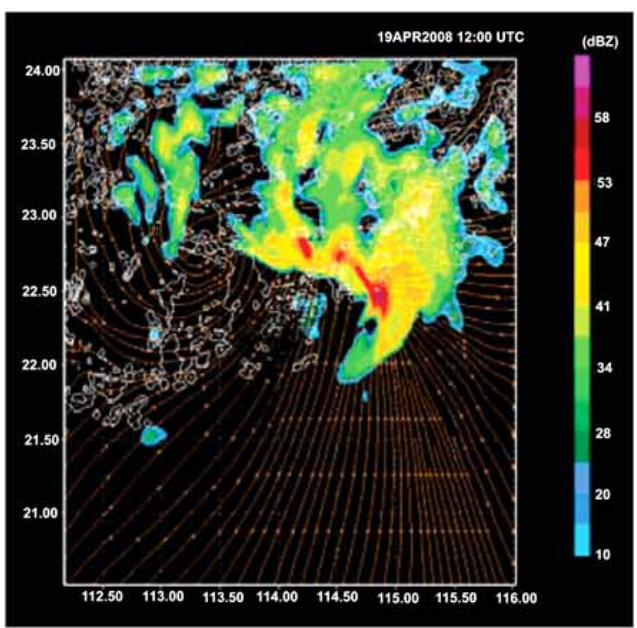

(a) cold start, no radar data

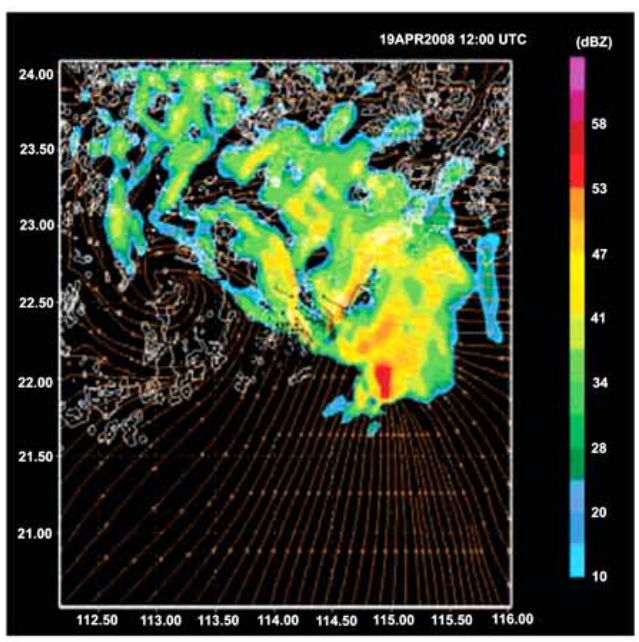

(c) cycling run, direct assimilation of radar data

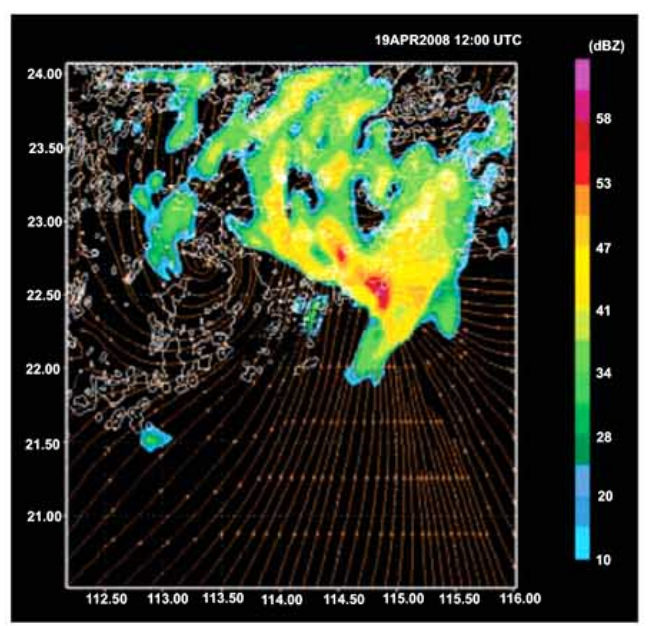

(b) cold start, with the assimilation of radar data

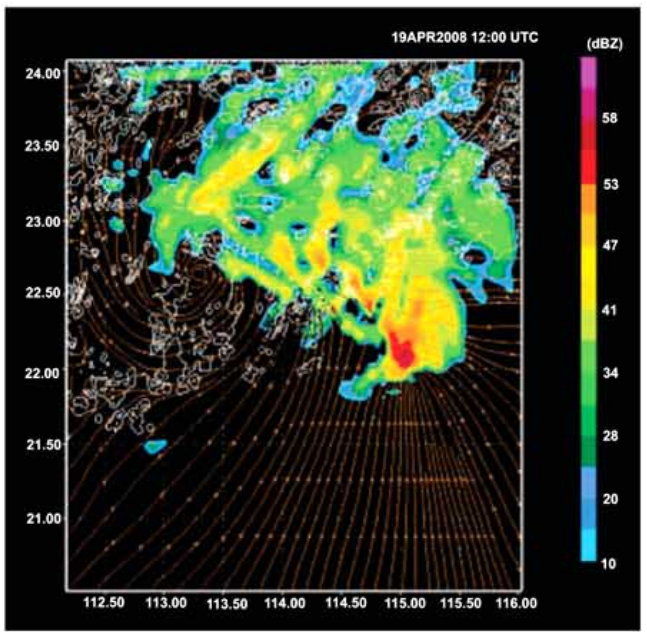

(d) cycling run, assimilating radar retrieved winds
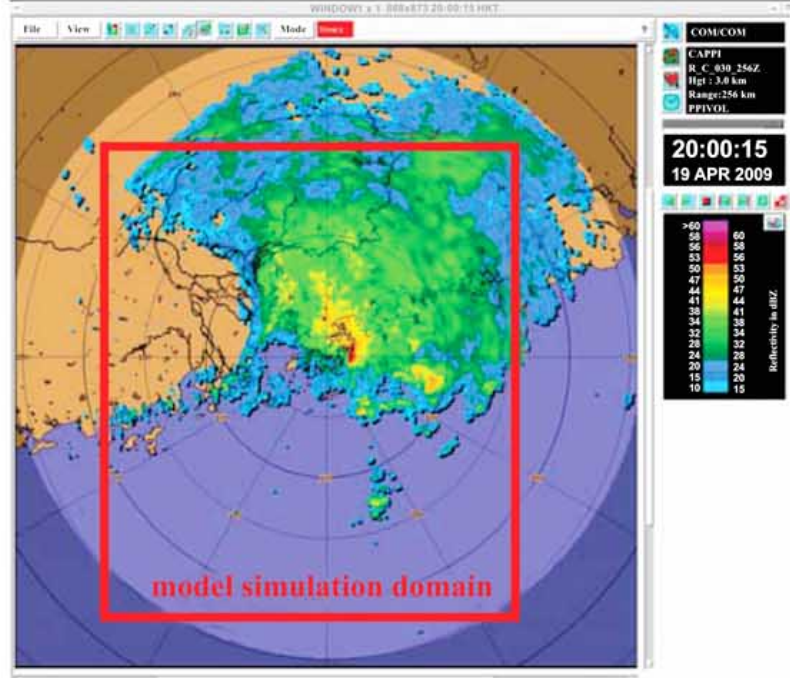

(e) actual radar reflectivity

Fig. (2). The simulated radar reflectivity (coloured contours) and streamlines for the four different model runs (a-d) at 12 UTC, 19 April 2008. Wind barbs are the simulated surface winds at the automatic weather stations in Hong Kong. The height contours (in white) are in 200 m. (e) Shows the actual radar reflectivity at the same time. 


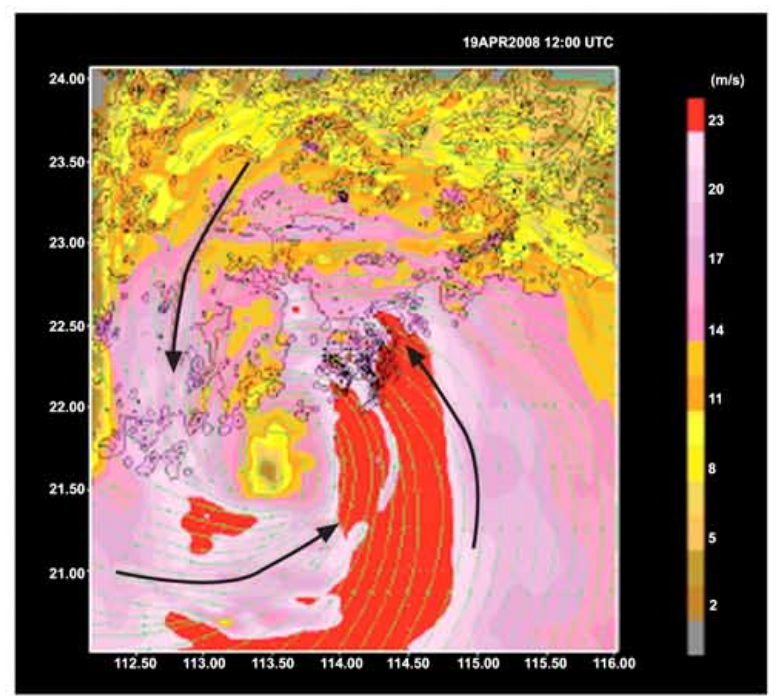

(a) cold start, no radar data

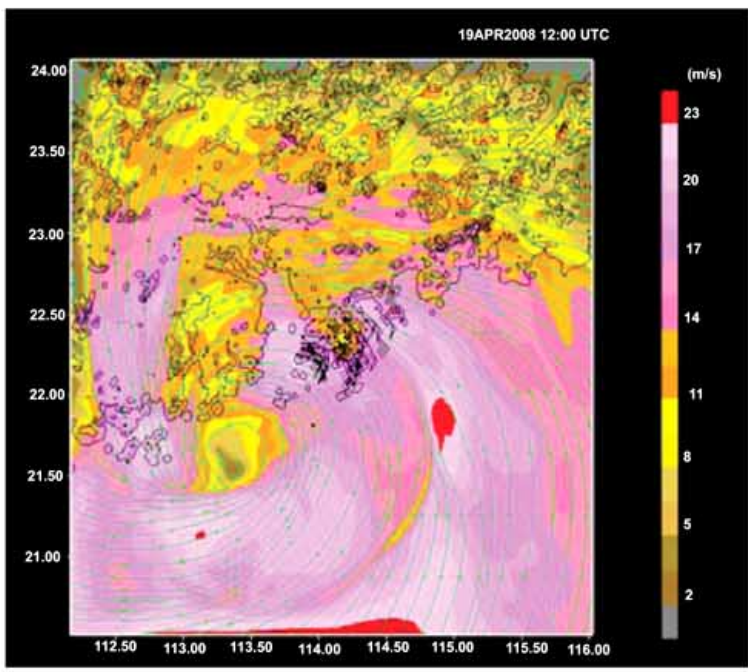

(c) cycling run, direct assimilation of radar data

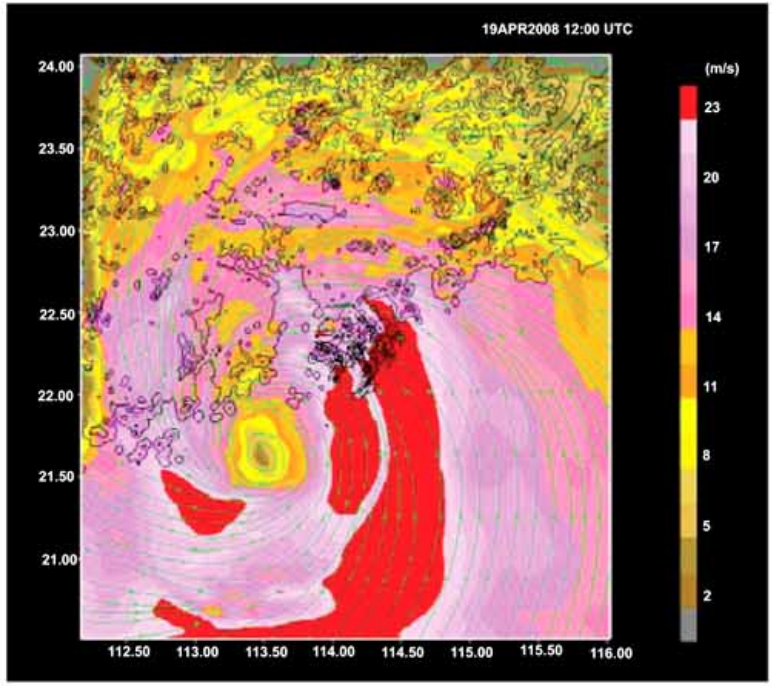

(b) cold start, with the assimilation of radar data



(d) cycling run, assimlating radar retrieved winds

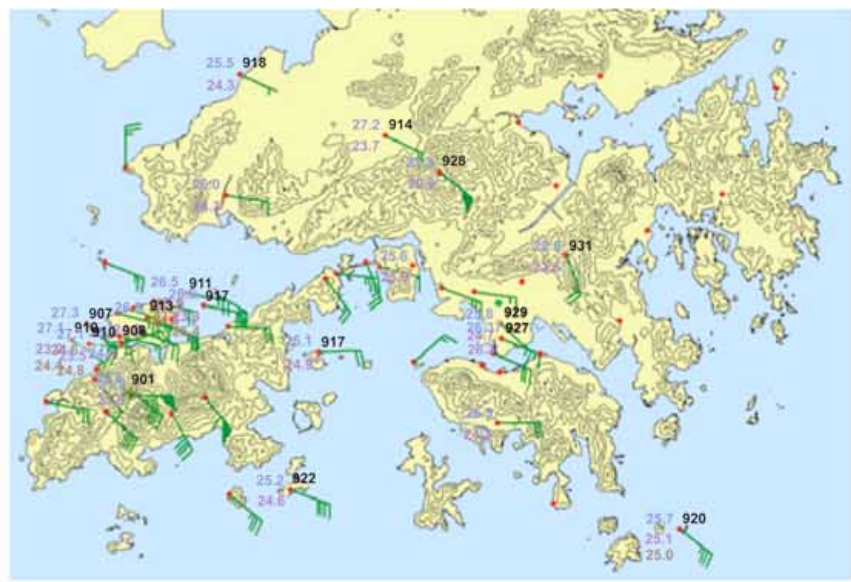

(e) actual surface wind observations in Hong Kong

Fig. (3). The simulated surface wind magnitude (coloured contours) and streamlines for the four different model runs (a-d) at 06 UTC, 6 August 2008. The black contours are height contours in $200 \mathrm{~m}$. The wind barbs over Hong Kong are simulated surface winds at the automatic weather stations within the territory. The major directions of the airflow are shown as arrows in (a). (e) shows the actual surface wind data in Hong Kong at the same time. Height contours are in $100 \mathrm{~m}$. 


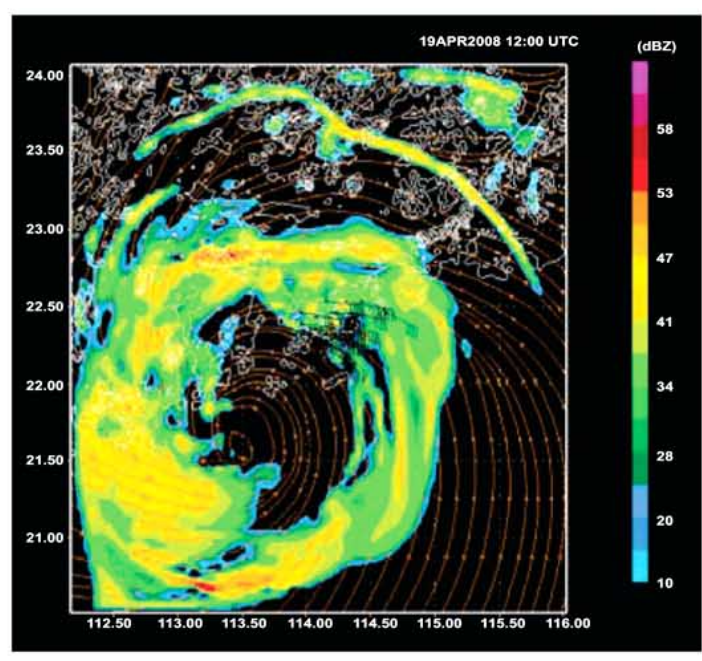

(a) cold start, no radar data

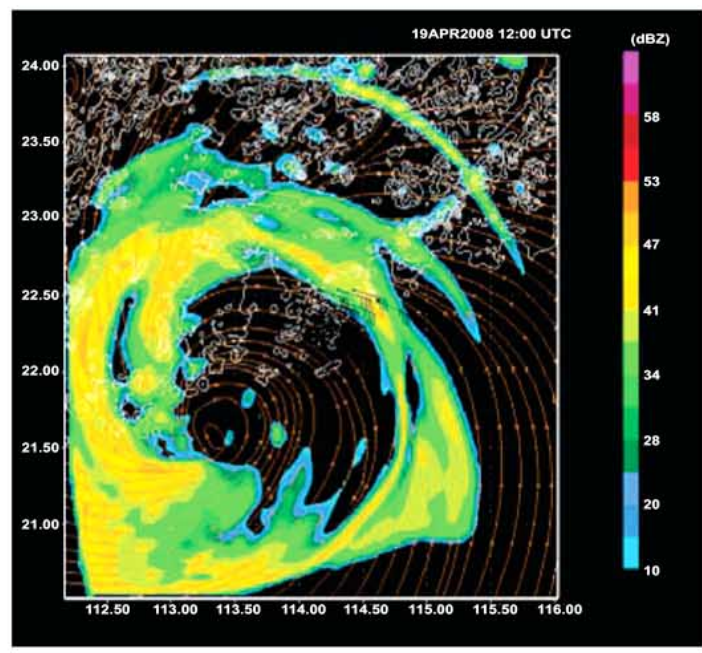

(c) cycling run, direct assimilation of radar data

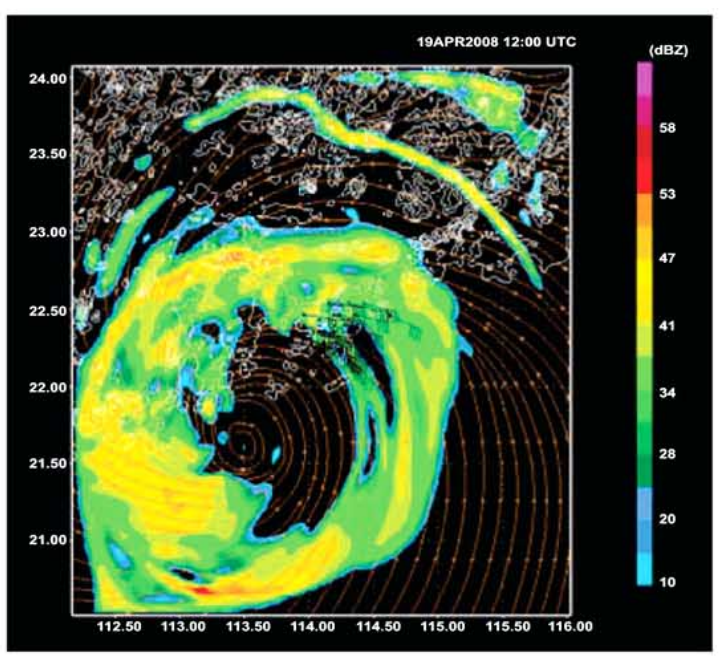

(b) cold start, with the assimilation of radar data

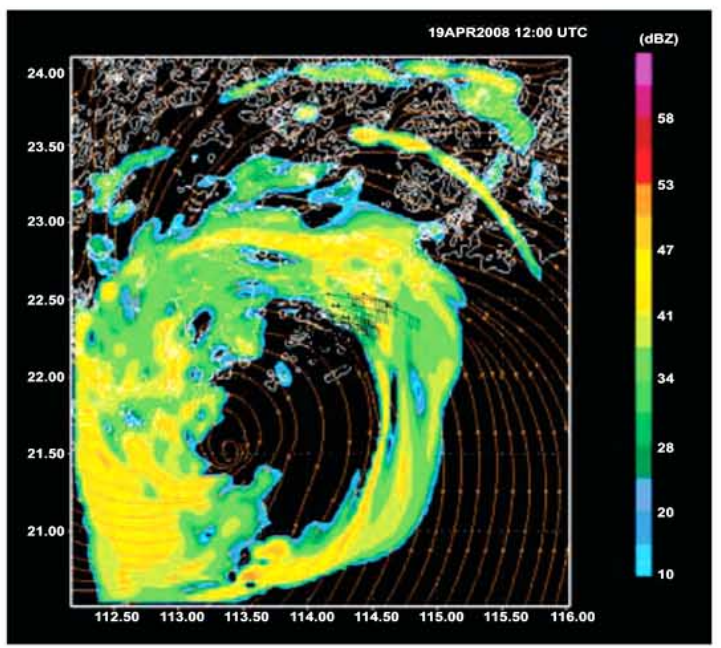

(d) cycling run, assimilating radar retrieved winds
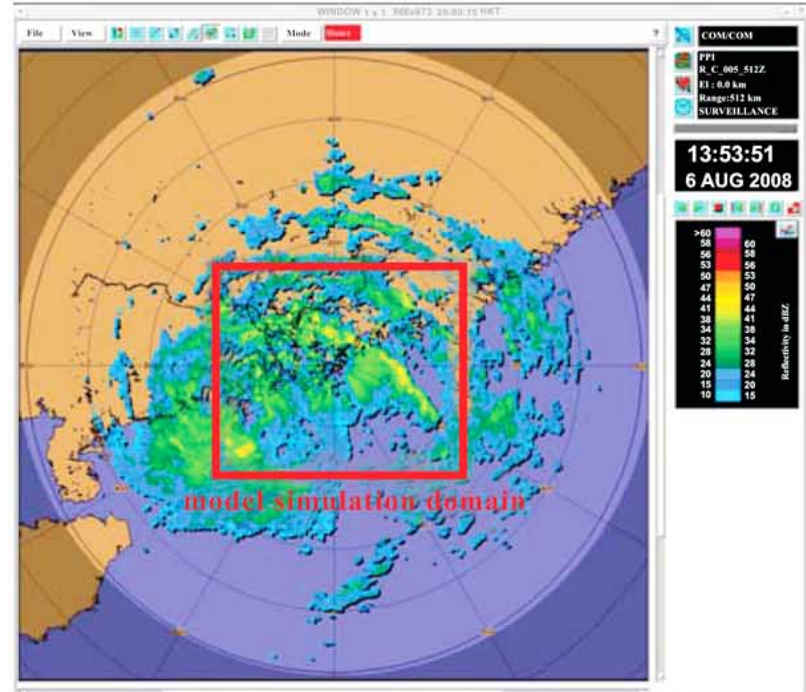

(e) actual radar reflectivity

Fig. (4). The simulated radar reflectivity (coloured contours) and streamlines for the four different model runs (a-d) at 06 UTC, 6 August 2008. Wind barbs are the simulated surface winds at the automatic weather stations in Hong Kong. The height contours (in white) are in 200 $\mathrm{m}$. (e) shows the actual radar reflectivity at the same time. 
2008 and run for three hours before data assimilation and another model run at 00 UTC, 6 August. The WRFsimulated surface wind magnitude and the streamlines for the various data assimilation runs after 6 hours are shown in Fig. (3a-d). The cold-start runs (a) and (b) forecast very strong winds over the territory and seas to the south, reaching $23 \mathrm{~m} / \mathrm{s}$ or more. On the other hand, the cycling runs (c) and (d) give generally lower wind speeds. In particular, there is just a small area of $23 \mathrm{~m} / \mathrm{s}$ wind speed (coloured red) in the cycling simulation with the direct assimilation of radar velocity and reflectivity data (Fig. 3c). Unfortunately there were no surface observations over the seas for direct comparison with the model simulation results. However, if we consider the wind observations over Hong Kong only (Fig. 3e), the strongest winds seem to be in the order of $17-$ $20 \mathrm{~m} / \mathrm{s}$ (35 - 40 knots) only, and there is no extensive area of surface wind magnitude reaching $23 \mathrm{~m} / \mathrm{s}$. Winds of the strength similar with that over Hong Kong were also recorded at Huang Mao Zhou (not shown).

The rain forecasts of the various model runs are given in Fig. (4a-d). Among these runs, the cycling simulation Fig. (4c) gives the stronger rain bands (simulated radar reflectivity of about $40 \mathrm{dBZ}$ ) located just to the north of Hong Kong, so that the territory is just clear of the influence of heavier rain. This is the most consistent with the actual radar observation (Fig. 4e). However, in all simulations, the radar-echo-free area associated with the eye of the tropical cyclone appears to be too large.

\section{CONCLUSIONS}

A number of experiments are conducted in this paper to find out the impact of the assimilation of radar data in the forecasting of heavy rain and strong winds associated with tropical cyclones. Two tropical cyclone cases in 2008 are considered. With this limited experiment, it appears that cycling run gives better results than cold-start run, and in particular the direct assimilation of radar velocity and reflectivity data seems to perform the best. In order to have more quantitative assessment of the performance of the various simulations, the time series of the wind and rain forecasts would need to be considered. Also comparison with upper air wind data over a longer period of time, e.g. wind profiler and AMDAR observations, would be useful to examine the quality of the forecasts. All these would be the subjects of further studies. Moreover, only two tropical cyclone cases are considered in this paper. The impact of radar data on the forecasting of tropical cyclones would be studied for more cases as well.

\section{REFERENCES}

[1] Barker DM, Huang W, Guo YR, Xiao QN. A three-dimensional (3DVAR) data assimilation system for use with MM5: Implementation and initial results. MWR 2004; 132: 897-914.

[2] Skamarock WC, Klemp JB, Dudhia J, et al. A description of the Advanced Research WRF Version 2, NCAR/TN-468+STR 2007; pp. 100

[3] Yang Y, Qiu CJ. Analysis on mesoscale circulation within a heavy rain system using Doppler radar data. Plateau Meteorol 2006; 25: 925-31 (in Chinese with English abstract).

[4] Yeung LHY, Chan PKY, Lai EST. Impact of radar rainfall data assimilation on short-range quantitative precipitation forecasts using four-dimensional variational analysis technique. $32^{\text {nd }}$ Conference on Radar Meteorology, American Meteorological Society, New Mexico 2005 (on-line proceedings).

[5] Zhao QY, Jin Y. High-resolution radar data assimilation for hurricane Isabel (2003) at landfall. Bull Am Meteorol Soc 2008; 89: 1355-72. 